\title{
Fetal and infant origins of cardiovascular disease
}

\author{
D J P Barker, C H D Fall
}

MRC Environmental Epidemiology Unit, Southampton General Hospital, Southampton SO9 4XY D J P Barker C H D Fall C H D Fall Professor Barker.
Babies who sustain intrauterine growth retardation are known to have structural and metabolic abnormalities. They may have, for example, disproportionate reduction in the size of some organs, including the liver. They have abnormal glucose-insulin metabolism, ${ }^{1}$ raised serum triglycerides, ${ }^{2}$ and high plasma growth hormone and cortisol ${ }^{3}$ concentrations.

A recent series of studies has now shown that abnormalities of structure and metabolism persist in small for dates babies and that they have an increased risk of coronary heart disease in adult life.

Among 1586 men born in the Jessop Hospital in Sheffield during 1907-24 death rates from coronary heart disease and stroke fell progressively between those with the lowest and highest weights, head circumferences, and ponderal indices (weight/length ${ }^{3}$ ) at birth. ${ }^{4}$ Similarly among a group of men born in Hertfordshire during 1911-30 those who weighed less at birth or at 1 year had higher coronary disease death rates. The death rates of men who weighed $8 \cdot 2$ $\mathrm{kg}$ (18 pounds) or less at 1 year of age were three times greater than those of men who weighed $12 \cdot 3 \mathrm{~kg}$ (27 pounds) or more. ${ }^{5}$

\section{Programming}

These findings have been interpreted as showing that coronary heart disease arises from fetal adaptations to an adverse environment in utero. In adapting to an adverse environment, to suboptimal nutrition in particular, the growth of certain fetal organs and tissues, including the liver and pancreas, is constrained while that of others, including the brain, may be spared. Numerous animal experiments have shown that poor nutrition during periods of rapid growth in early life may permanently change the structure and physiology of a range of organs and tissues. ${ }^{67}$ This phenomenon is known as programming. It occurs because cell numbers, vascularisation, and metabolism in the body's organs and systems are established during brief periods of early growth. There are critical windows of time during which maturation must be achieved, and failure of maturation is to some extent irrecoverable.

cardiovascular disease. This explanation is not likely to be correct because birth weight does not seem to be strongly genetically determined. Comparisons of the birth weights of half siblings show that whereas those related through the mother tend to have similar birth weights those related through the father do not. ${ }^{8}$ Studies of the birth weights of first born children and mothers and daughters similarly suggest that genetic factors play only a small part in determining birth weight. Neither in fetal growth nor in most cases of cardiovascular disease do purely genetic influences have a major effect and it is necessary to look for another link between them.

\section{Hypertension}

Following the demonstration that low rates of fetal and infant growth are linked to death from coronary heart disease samples of middle aged men and women born in three areas of England, Hertfordshire, Preston and Sheffield, have been examined. Records of their early growth had been preserved.

In each sample systolic and diastolic blood pressure fell progressively between those. who had low birth weight and those who had high birth weight. ${ }^{910} \mathrm{~A}$ similar association between birth weight and adult blood pressure was found in the 1946 national cohort. These associations do not depend on shortened gestation, and it can be concluded that high blood pressure is initiated by processes associated with reduced growth in utero. Raised blood pressure is not confined to people who sustained intrauterine growth retardation defined by birth weight at the lowest centiles. Blood pressure falls progressively between people who had the lowest and highest birth weight. Examination of birth measurements identifies two groups of babies whose birth weights are within the normal range but who develop high blood pressure as adults. One group is thin, having a low ponderal index, the other group is short, having a lower body length than would be expected from their head circumference. " Thin babies are recognised in clinical practice in that those with sufficiently low birth weight to qualify as growth retarded are termed 'asymmetric'. Short babies are not usually recognised clinically: they can have above average birth weight. The pattern of infant growth in the two groups differs. Thin babies tend to 'catch up' in weight whereas short babies do not. ${ }^{1213}$

Though the relation between systolic pressure An alternative explanation for the close link between early growth and coronary heart disease is that the genes which determine low weight gain in utero and during infancy also determine 
with increasing age. ${ }^{10} \mathrm{An}$ interpretation of this is that the association between reduced fetal growth and blood pressure is initiated in utero and thereafter amplified throughout life. The existence of initiating and amplification mechanisms in the aetiology of essential hypertension was first postulated by Folkow. ${ }^{14}$ We can speculate on the processes which underlie them. The initiating process could be changes in fetal blood flow or in the activity of a trophin or mitogen leading to changes in the vessel wall and subsequently a rise in blood pressure. Suggested trophins include cortisol, insulin, and insulinlike growth factor-I (IGF-I) (somatomedin C), catecholamines, and angiotensin II.

The feedback mechanism that amplifies the initiating effects with age could depend on progressive changes in the structure or compliance of blood vessels. In humans and in animals vascular structure and compliance change with haemodynamic load. ${ }^{15}$ An increase in peripheral resistance and pulse pressure in early life could alter structure and reduce compliance, which in turn would increase pulse pressure. A feedback mechanism could thereby become established and amplify blood pressure from birth to old age.

In one study of men and women in Preston there was, as expected, a fall in blood pressure associated with increasing birth weight. ${ }^{9}$ There was also a hitherto unsuspected increase in blood pressure with increasing placental weight. Subjects with mean systolic pressures of $150 \mathrm{~mm} \mathrm{Hg}$ or more comprised a group who as babies were relatively small in relation to the size of their placentas. In man and animals disproportionately large placental size may be a consequence of maternal undernutrition. It occurs in babies whose mothers were anaemic during pregnancy. ${ }^{16}$ It can be produced in sheep by depriving the ewe of food in early pregnancy. ${ }^{17} \mathrm{We}$ therefore suspect that maternal undernutrition may be an important influence in determining high blood pressure in the next generation. Recent studies of 4 year old children in Salisbury have shown similar associations between birth weight, placental weight, and blood pressure as were found in older people. ${ }^{18}$ This leads to the conclusion that maternal undernutrition still affects fetal growth and later blood pressure today, a conclusion that is consistent with the high incidence of pregnancy anaemia.

\section{Non-insulin dependent diabetes}

Insulin is an obvious possible link between fetal growth and coronary heart disease. Together with the IGFs it is thought to have a central role in the regulation of fetal growth; and diabetes is associated with an increased risk of coronary heart disease.

Standard glucose tolerance tests were carried out on samples of men and women in the three areas of England. ${ }^{1920}$ The percentage of people with impaired glucose tolerance, defined by a two hour plasma glucose concentration of $7 \cdot 8$ to $11.0 \mathrm{mmol} / \mathrm{l}$ at two hours, or non-insulin dependent diabetes, defined by a two hour plasma glucose concentration of $11 \cdot 1 \mathrm{mmol} / \mathrm{l}$ or more, fell progressively with increasing birth weight and increasing weight at 1 year. Among
370 men in Hertfordshire, for example, the relative risk of impaired glucose tolerance was eight times higher in those who weighed $8.2 \mathrm{~kg}$ or less at 1 year than in men who weighed $12.3 \mathrm{~kg}$ or more. ${ }^{19}$ In Preston men and women who had impaired glucose tolerance or non-insulin dependent diabetes had lower mean birth weight, a smaller head circumference at birth, and were thinner at birth - as defined by a low ponderal index. ${ }^{20}$ They also had a higher ratio of placental weight to birth weight. There was, however, no difference in their duration of gestation. Low birth weight and impaired glucose-insulin metabolism are therefore associated through reduced rates of fetal growth, and again the association with a high placental to birth weight ratio suggests the influence of maternal undernutrition.

Both deficiency of insulin and resistance to its effects are thought to be important in the pathogenesis of non-insulin dependent diabetes. ${ }^{21}$ Among the sample of men in Hertfordshire those who had the lowest weights at 1 year of age had high plasma concentrations of 32-33 split proinsulin. ${ }^{19}$ High concentrations of 32-33 split proinsulin are thought to indicate production of insulin by a comparatively small complement of pancreatic $\beta$ cells. The observation therefore suggests that men who had low weight at 1 year sustained impaired development of the pancreas during its period of rapid growth in fetal life and infancy. This interpretation is consistent with the occurrence of impaired development of the endocrine pancreas found in babies with intrauterine growth retardation, ${ }^{22}$ and with studies in rats which show that undernutrition in early life permanently impairs the insulin secretory response to glucose.

Men and women who had low birth weight have a high prevalence of syndrome $X$, a syndrome associated with marked insulin resistance. ${ }^{23}$ Patients with this syndrome have impaired glucose tolerance, hypertension, high serum triglyceride concentrations, and low serum high density lipoprotein concentrations. The prevalence of syndrome $\mathrm{X}$ fell progressively from $30 \%$ in men who weighed $2500 \mathrm{~g}(5.5$ pounds) or less at birth to $6 \%$ in men who weighed $4300 \mathrm{~g}$ ( 9.5 pounds) or more. The relative risk, after adjusting for current body mass, fell from 18 to 1 .

People with syndrome $\mathrm{X}$ tended to have been thin at birth, with a low ponderal index. ${ }^{23}$ Insulin tolerance tests carried out on 103 subjects in Preston, either normoglycaemic or with impaired glucose tolerance, have since confirmed that low ponderal index at birth is associated with insulin resistance in adult life (D I W Phillips, unpublished). The processes which link thinness at birth with insulin resistance in adult life are not known. Studies of patients with non-insulin dependent diabetes, using a euglycaemic clamp, have shown that peripheral tissues, particularly skeletal muscle, are an important site of insulin resistance. ${ }^{21}$ Muscle biopsy specimens have shown that insulin resistance is associated with a lower density of capillaries in muscle, a lesser proportion of type 1 muscle fibres, and a greater proportion of type 2B fibres. Transcapillary insulin transport is a 
rate limiting step in insulin action. Babies born at term with a low ponderal index have a reduced mid-arm circumference which implies that they have a low muscle bulk as well as less subcutaneous fat. It is therefore possible that thinness at birth is associated with abnormalities in muscle structure and function that persist into adult life and interfere with the ability of insulin to promote glucose intake.

\section{Fibrinogen and cholesterol}

The two strongest predictors of risk of coronary heart disease in an adult man are raised plasma concentrations of fibrinogen and cholesterol, especially low density lipoprotein (LDL) cholesterol. Both are related to specific patterns of reduced rates of early growth. Plasma fibrinogen concentrations are increased in men who were short at birth in relation to their head circumference, and whose infant growth was less than that predicted by their birth weight. ${ }^{24}$ Concentrations of apolipoprotein B, the apoprotein associated with LDL cholesterol, are also raised in men who had low infant growth rates. ${ }^{25}$ The high adult concentrations of fibrinogen and apolipoprotein B associated with shortness at birth and reduced infant growth may be a persisting response to impaired liver development during a critical early phase.

Infants who were short at birth, in consequence of prolonged maternal undernutrition, may have persisting defects in their growth hormone and IGF axis. They have exaggerated responses to growth hormone releasing factor and lower IGF-I concentrations, suggesting a degree of growth hormone resistance. ${ }^{26}$ One possible interpretation is that the normal evolution of their hepatic growth hormone receptors may have been attenuated.

A recent hypothesis suggests that babies who are thin, short, or symmetrically small at birth experienced undernutrition at different stages of gestation, and that adaptations to undernutrition lead to persisting changes in the levels of hormone secretion and in the sensitivity of tissues to them. ${ }^{27}$ Undernutrition during gestation could reprogramme the glucose-insulin and the growth hormone-IGF relationships. Reprogramming of these relationships may be analogous to the programming of the thyroid stimulating hormone (TSH)-thyroxine axis in congenital hypothyroidism, where the TSH: thyroxine ratio remains high. Insulin resistance and deficiency are associated with cardiovascular disease in adult life. Both growth hormone and IGF-I increase cardiac output, stimulate ventricular growth, and influence angiogenesis and IGF-I has its most marked anabolic effects on cardiac muscle.

\section{Conclusion}

Research into the nutritional and other influences that modulate the growth of the fetus and infant and permanently programme its metabolism is now a priority. It may hold the key to preventing cardiovascular disease and other important disorders in adult life.

1 Collins JE, Leonard JV, Teal D, et al. Hyperinsulinaemia and hypoglycaemia in small for dates babies. Arch Dis Child 1990; 65: 1118-20.

2 Fosbrook AS, Wharton BA. Plasma lipids in umbilical cord blood from infants of normal and low birthweight. Biol blood from infants of

3 Haymond MW, Karl IE, Pagliara AS. Increased gluconeogenic substrates in the small for gestational age infant N Engl F Med 1974; 291: 322-8.

4 Barker DJP, Osmond C, Simmonds SJ, Wield GA. The relation of small head circumference and thinness at birth to death from cardiovascular disease in adult life. $B M \mathcal{F} 1993$ 306: 422-6.

5 Barker DJP, Winter PD, Osmond C, Margetts B, Simmonds SJ. Weight in infancy and death from ischaemic heart disease. Lancet 1989; ii: $577-80$.

6 Winick M, Noble A. Cellular response in rats during malnutrition at various ages. F Nutr 1966; 89: 300-6.

7 Hahn P. Effect of litter size on plasma cholesterol and insulin and some liver and adipose tissue enzymes in adult rodents. 7 Nutr 1984; 114: 1231 .

8 Morton NE. The inheritance of human birthweight. Ann Hum Genet 1955; 19: 125-34.

9 Barker DJP, Bull AR, Osmond C, Simmonds SJ. Fetal and placental size and risk of hypertension in adult life. $B M \mathcal{F}$ 1990; 301: 259-62.

10 Law CM, de Swiet M, Osmond C, et al. Initiation of hypertension in utero and its amplification throughout life. BMF 1993; 306: 24-7.

11 Barker DJP, Godfrey KM, Osmond C, Bull A. The relation of fetal length, ponderal index and head circumference to blood pressure and the risk of hypertension in adult life. Paediat Perinat E pidemiol 1992; 6: 35-44

12 Holmes GE, Miller HC, Hassanein K, Lansky SB, Goggin JE. Postnatal somatic growth in infants with atypical fetal growth patterns. Am 7 Dis Child 1977; 3: 1078-83.

13 Villar J, Smeriglio V, Martorell R, Brown CH, Klein RE. Heterogeneous growth and mental development of intrauterine growth retarded infants during the first 3 years of life. Pediatrics 1984; 74: 783-91.

14 Folkow B. Cardiovascular structural adaptation: its role in the initiation and maintenance of primary hypertension. Clin Sci 1978; 55: 3-22S.

15 Berry C. Hypertension and arterial development: long-term considerations. Br Heart F 1978; 40: 709-17.

16 Godfrey KM, Redman CWG, Barker DJP, Osmond C. The effect of maternal anaemia and iron deficiency on the ratio of fetal weight to placental weight. Br $\mathcal{F}$ Obstet Gynaecol 1991; 98: 886-91.

17 McCrabb GJ, Egan AR, Hosking BJ. Maternal undernutrition during mid-pregnancy in sheep. Placental size and its during mid-pregnancy in sheep. Placental size and its relationship to calcium

18 Law C, Barker D, Bull A, Osmond C. Maternal and fetal influences on blood pressure. Arch Dis Child 1991; 66: 1291-5.

19 Hales CN, Barker DJP, Clark PMS, et al. Fetal and infant growth and impaired glucose tolerance at age 64 years. $B M \mathcal{F}$ 1991; 303: 1019-22.

20 Phipps K, Barker DJP, Hales CN, Fall CHD, Osmond C, Clark PMS. Fetal growth and impaired glucose tolerance in men and women. Diabetologia 1993; 36: 225-8.

21 DeFronzo RA. The triumvirate: beta cell, muscle, liver. A collusion responsible for NIDDM. Diabetes 1988; 37: 66787.

22 Van Assche FA, Deprins F, Aerts L, Verjans $M$. The endocrine pancreas in the small-for-dates infants. $\mathrm{Br} \mathcal{F}$ Obstet Gynaecol 1977; 84: 751-3.

23 Barker DJP, Hales CN, Fall CHD, Osmond C, Phipps K, Clark PMS. Type 2 (non-insulin-dependent) diabetes mellitus, hypertension and hyperlipidaemia (syndrome $\mathrm{X}$ ) relation to reduced fetal growth. Diabetologia 1993; 36: 62 7.

24 Barker DJP, Meade TW, Fall CHD, et al. Relation of fetal and infant growth to plasma fibrinogen and factor VII concentrations in adult life. $B M \mathcal{F} 1992 ; 304$ : 148-52.

25 Fall CHD, Barker DJP, Osmond C, Winter PD, Clark PMS, Hales CN. Relation of infant feeding to adult serum cholesterol concentration and death from ischaemic heart disease. $B M \mathcal{F} 1992 ; 304$ : 801-5.

26 Job JC, Chatelain P, Rochiccioli P, Ponte C, Oliver M, Sagard L. Growth hormone response to a bolus injection of $1-44$ growth-hormone-releasing hormone in very short children with intrauterine onset of growth failure. Horm Res 1990; 33 : 161-5.

27 Barker DJP, Gluckman PD, Godfrey KM, Harding JE, Owens JA, Robinson JS. Fetal nutrition and cardiovascular disease in adult life. Lancet 1993 (in press). 